\title{
Article
}

\section{Sex differences in knee loading in recreational runners}

Sinclair, Jonathan Kenneth and Selfe, James

Available at http://clok.uclan.ac.uk/12567/

Sinclair, Jonathan Kenneth ORCID: 0000-0002-2231-3732 and Selfe, James (2015) Sex differences in knee loading in recreational runners. Journal of Biomechanics, 48 (10). pp. 2171-2175.

It is advisable to refer to the publisher's version if you intend to cite from the work.

For more information about UCLan's research in this area go to

http://www.uclan.ac.uk/researchgroups/ and search for < name of research Group>.

For information about Research generally at UCLan please go to

http://www.uclan.ac.uk/research/

All outputs in CLoK are protected by Intellectual Property Rights law, including Copyright law. Copyright, IPR and Moral Rights for the works on this site are retained by the individual authors and/or other copyright owners. Terms and conditions for use of this material are defined in the policies page.

\section{CLoK}

Central Lancashire online Knowledge www.clok.uclan.ac.uk

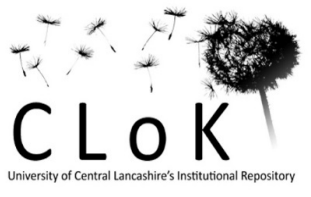




\section{Sex differences in knee loading in recreational runners}

ARTICLE in JOURNAL OF BIOMECHANICS • MAY 2015

Impact Factor: 2.75 · DOI: 10.1016/j.jbiomech.2015.05.016

2 AUTHORS:

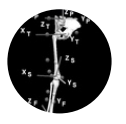

Jonathan Sinclair

University of Central Lancashire

182 PUBLICATIONS 270 CITATIONS

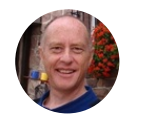

James Selfe

University of Central Lancashire

186 PUBLICATIONS 876 CITATIONS

SEE PROFILE

SEE PROFILE 


\title{
Short communication
}

\section{Sex differences in knee loading in recreational runners}

\author{
Q1 J. Sinclair ${ }_{\wedge}^{\mathrm{a}, *}, \mathrm{~J}$. Selfe, ${ }^{\mathrm{b}}$ \\ a Centre for Applied Sport and Exercise Sciences, University of Central Lancashire, Preston PR1 2HE, Lancashire, UK \\ $62{ }^{\mathrm{b}}$ Department of Allied Health Professionals, University of Central Lancashire, Lancashire, UK
}

\section{A R T I C L E I N F O}

Article history:

Accepted 15 May 2015

Keywords:

Patellofemoral contact

Sex

Running

Injuries

\begin{abstract}
A B S T R A C T
Patellofemoral pain is the most common chronic pathology in recreational runners. Female runners are at greater risk of developing patellofemoral pain, although the exact mechanism behind this is not fully understood. This study aimed to determine whether female recreational runners exhibit distinct knee loading compared to males. Fifteen males and 15 females recreational runners underwent 3D running analysis at $4.0 \mathrm{~m} \mathrm{~s}^{-1} \pm 5 \%$. Sagittal/coronal joint moments, patellofemoral contact forces (PTF) and pressures (PCP) were compared between sexes. The results show that females exhibited significantly greater knee extension $\left(p<0.008, \mathrm{p}^{2}=0.27\right.$ : males $=3.04$; females $\left.=3.47 \mathrm{~N} \mathrm{~m} \mathrm{~kg}^{-1}\right)$ and abduction $\left(p<0.008, \mathrm{p \eta}^{2}=0.28\right.$ : males $=0.54$; females $\left.=0.82 \mathrm{~N} \mathrm{~m} \mathrm{~kg}^{-1}\right)$ moments as well as PTF $(p<0.008$, $\mathrm{p} \eta^{2}=0.29: \quad$ males $=3.25 ;$ females $=3.84$ B.W. $)$ and PCP $\left(p<0.008, \quad \mathrm{p} \eta^{2}=0.26\right.$ : males $=7.96$; females $=9.27 \mathrm{MPa}$ ) compared to males. Given the proposed relationship between knee joint loading and patellofemoral pathology, the current investigation provides insight into the incidence of patellofemoral pain in females.
\end{abstract}

(c) 2015 Published by Elsevier Ltd.

\section{Introduction}

It has been shown that $19.4-79.3 \%$ of all who participate in recreational running activities will suffer from a chronic pathology over the course of one year (van Gent et al., 2007). Patellofemoral pain syndrome has been demonstrated as the most common 3 Q3 chronic injury in runners (Taunton et al., 2003), accounting for 20$40 \%$ of all knee disorders (DeHaven and Lintner, 1986; Kannus et al., 1987). The patellofemoral joint itself involves the distal and anterior aspects of the femur, patella, and their articular surfaces (Tumia and Maffulli, 2002). The patella serves to enhance the effective moment arm of the quadriceps muscle group and reduces the mechanical effort required to extend the knee joint (Tumia and Maffulli, 2002).

Patellofemoral symptoms are defined by pain which initiates as function of the contact between the posterior aspect of the patella and distal end of the femur during dynamic activities (Besier et al., 2005). Patellofemoral pain symptoms are debilitating and may severely restrict participation in athletic activities (Selfe et al., 2013; Witvrouw et al., 2014). Patellofemoral pain has also been cited as a potential precursor to the progression of osteoarthritic symptoms in later life (Crossley, 2014; Thomas et al., 2010). A number of biomechanical mechanisms have been linked to the

\footnotetext{
* Corresponding author.

E-mail address: JKSinclair@uclan.ac.uk (
}

etiology of patellofemoral pain. However, habitual and excessive contact stresses between the patella and femur (LaBella, 2004; Ho et al., 2012) as well as enhanced knee abduction moments (Sigward et al., 2012; Myer et al., 2015) are most strongly associated with the initiation of patellofemoral symptoms.

Female recreational runners are 2-3 times more likely to suffer from patellofemoral pain in comparison to males (Robinson and Nee, 2007; Boling et al., 2010). It has been postulated that anatomical, neuromuscular and hormonal influences contribute to the enhanced incidence of patellofemoral disorders in females (Robinson and Nee, 2007). However, the exact mechanisms behind the incidence of patellofemoral pain in female runners remain unknown. This indicates that there is a clear need to investigate the loads experienced by the patellofemoral joint in female runners in relation to males in order to gain further insight into the increased incidence of patellofemoral disorders in females.

Quantification of patellofemoral forces during dynamic activities is problematic as direct measurements of in vivo patellofemoral stresses are impractical (Mason et al., 2008). We must therefore rely on computational techniques to estimate the loads experienced by the patellofemoral joint. Early researchers examined patellofemoral forces using in vitro cadaveric models (Huberti and Hayes, 1984; Ahmed et al., 1987). Whilst these studies provided important information regarding the mechanics of the knee joint the patellofemoral joint loads could not be generalized to in vivo conditions (Powers et al., 2006). Mathematical modeling of 
the patellofemoral joint is now the most commonly utilized procedure. Approaches to modeling patellofemoral joint forces include both two-dimensional and three-dimensional (3D) techniques (Powers et al., 2006). Mathematical techniques model the patellofemoral joint as a pulley mechanism whereby the patellofemoral contact force is produced by the force generated in the quadriceps (Powers et al., 2006). In recent years musculoskeletal simulation techniques have also been developed for the quantification of lower extremity joint reactions forces. Musculoskeletal simulation uses inverse kinematics to estimate the forces required to produce dynamic movements (Delp et al., 2007).

The aim of the current investigation was to determine whether female recreational runners exhibit distinct patellofemoral loading patterns in relation to their male counterparts. The current study tests the hypothesis that females will exhibit increased knee joint loading in comparison to males.

\section{Methods}

\subsection{Participants}

Fifteen males (age $28.80 \pm 4.23$ years, height $1.80 \pm 0.13 \mathrm{~m}$ and mass $79.07 \pm 6.88 \mathrm{~kg}$ ) and 15 females (age $27.67 \pm 7.52$ years, height $1.67 \pm 0.19 \mathrm{~m}$ and mass $63.33 \pm 10.07 \mathrm{~kg}$ ) recreational runners took part in this investigation. Both males and females were characterized as recreational runners who trained at least 3 times per week and had a minimum of five years of distance running experience. The male group had a mean personal best $10 \mathrm{~km}$ time of $43 \pm 5 \mathrm{~min}$ and the females $49 \pm 4 \mathrm{~min}$. Runners were all considered to exhibit a rearfoot strike pattern as they exhibited first peak in their vertical ground reaction force (GRF) time-curve (Cavanagh and Lafortune, 1980). Ethical approval was obtained from the University.

\subsection{Procedure}

Participants completed 10 running trials across a $22 \mathrm{~m}$ laboratory at $4.0 \mathrm{~m} \mathrm{~s}^{-1} \pm 5 \%$, striking an embedded force platform (Kistler instruments, Model 9281CA) which operated at $1000 \mathrm{~Hz}$ with their right foot. 3D marker trajectories were collected using an eight camera motion capture system at $250 \mathrm{~Hz}$. Kinematic and GRF data were obtained synchronously using Qualisys track manager software (Qualisys Medical AB, Goteburg, Sweden). Participants all wore the same footwear Asics 2160, in sizes 4-10 UK sizing. As these footwear were novel to participants, they were given a 5 min period to familiarize. This involved running through the testing area without concern for striking the force platform (Sinclair et al., 2013).

The shank and thigh segments were delineated using the calibrated anatomical systems technique (Cappozzo et al., 1995). Retroreflective markers were positioned onto the medial and lateral malleoli, epicondyles of the femur and greater trochanter. Tracking clusters were positioned onto the segments. Static trials allowed the anatomical markers to be referenced in relation to the tracking clusters.

\subsection{Data processing}

GRF and marker data were filtered at $50 \mathrm{~Hz}$ and $15 \mathrm{~Hz}$ using a low-pass Butterworth 4th order filter and processed using Visual 3-D (C-Motion, Germantown, MD, USA). Joint kinetics were computed using Newton-Euler inverse-dynamics, allowing net knee joint moments to be calculated. To quantify joint moments segment mass, segment length, GRF and angular kinematics were utilized using the procedure previously described by Sinclair
(2014). The net joint moments were normalized by dividing by body mass $\left(\mathrm{N} \mathrm{m} \mathrm{kg}^{-1}\right)$.

Knee loading was examined through extraction of peak knee extensor/abduction moments, patellofemoral contact force (PTF) and patellofemoral contact pressure (PCP). PTF was normalized by dividing the net PTF by body weight (B.W.). PTF loading rate (B.W. $\mathrm{s}^{-1}$ ) was calculated as a function of the change in PTF from initial contact to peak force divided by the time to peak force. These variables were extracted from each of the 10 trials and the data was then averaged within subjects for statistical analysis. Knee joint kinetic curves were time normalized to stance and were ensemble averaged across subjects for graphical purposes.

PTF during running was estimated using knee flexion angle $(k f)$ and knee extensor moment (KEM) through the biomechanical model of Ho et al. (2012). This model has been utilized previously to resolve differences in PTF and PCP in different footwear (Bonacci et al., 2013; Kulmala et al., 2013; Sinclair, 2014) and between those with and without patellofemoral pain (Heino and Powers, 2002). The model has also been shown to be sufficiently sensitive to detect differences in PTF between sexes (Sinclair and Bottoms, 2015).

The effective moment arm distance $(\mathrm{m})$ of the quadriceps muscle (QM) was calculated as a function of $k f$ using a non-linear equation, based on information presented by van Eijden et al. (1986):

\section{$\mathrm{QM}=0.00008 k f^{3}-0.013 k f^{2}+0.28 k f+0.046$}

The force $(\mathrm{N})$ of the quadriceps (FQ) was calculated using the below formula:

$\mathrm{FQ}=\mathrm{KEM} / \mathrm{QM}$

Net PTF $(\mathrm{N})$ was estimated using the FQ and a constant $(C)$ : $\mathrm{PTF}=\mathrm{FQ} * C$

$C$ was described in relation to $\mathrm{kf}$ using a curve fitting technique based on the non-linear equation described by van Eijden et al. (1986):

\section{$C=\left(0.462+0.00147 * k f^{2}-0.0000384 * k f^{2}\right)$ \\ $/\left(1-0.0162 * k f+0.000155 * k f^{2}-0.000000698 * k f^{3}\right)$}

PCP (MPa) was calculated using the net PTF divided by the patellofemoral contact area. The contact area was described using the Ho et al. (2012) recommendations by fitting a 2nd order polynomial curve to the data of Powers et al. (1998) showing patellofemoral contact areas at varying levels of $\mathrm{kf}$.

$\mathrm{PCP}=\mathrm{PTF} /$ contact area

\subsection{Statistical analysis}

Sex differences in knee kinetics were examined using independent $t$-tests. The alpha level was adjusted to $p \leq 0.008$ using a Bonferroni correction. Effect sizes were calculated using partial $\operatorname{eta}^{2}\left(\mathrm{p \eta}^{2}\right)$. The data was pre-screened for normality using a Shapiro-Wilk. Statistical procedures were conducted using SPSS v22.0.

\section{Results}

Table 1 and Fig. 1 present the sex differences in patellofemoral load during the stance phase of running. Although the knee kinetic curves were qualitatively similar, the results also indicate that patellofemoral kinetic parameters were significantly influenced as a function of sex.

Females exhibited significantly greater peak knee extensor moments compared to males (Fig. 1a; Table 1). Females also had 
1 greater PTF and PTF load rate (Fig. 1b; Table 1). In addition females 2 exhibited a significantly increased PCP (Fig. 1c; Table 1). Finally it 3 was documented that females demonstrated a significantly 4 increased peak knee abduction moment compared to males 5 (Fig. 1d; Table 1). et al., 2011). Stearns et al. (2013) showed that weakness of the hip musculature resulted in a compensatory strategy whereby females relied more heavily on the knee extensor moment to absorb impact forces. In addition, female runners have also been shown to loads in comparison to males (Greenhalgh and Sinclair, 2014). An enhanced plantarflexion contribution from the ankle joint may also be a mechanism by which the loads at the knee joint are reduced in male runners. With an enhanced plantarflexion involvement the function of the knee joint as an energy absorber may be reduced in male runners, leading to a reduction in the loads experienced by the knee joint structures (Kulmala et al., 2013;

A further important finding from this study is that females exhibited a greater peak coronal plane abduction moment compared to males. Enhanced knee abduction moments are known to

Table 1

Patellofemoral kinetics as a function of gender.

\begin{tabular}{|c|c|c|c|c|c|}
\hline & \multicolumn{2}{|l|}{ Male } & \multicolumn{2}{|c|}{ Female } & \multirow[t]{2}{*}{ Statistical analysis } \\
\hline & Mean & $S D$ & Mean & $S D$ & \\
\hline $\begin{array}{l}\text { Peak knee extensor } \\
\text { moment }\left(\mathrm{N} \mathrm{m} \mathrm{kg}^{-1}\right)\end{array}$ & 3.04 & 0.30 & 3.47 & 0.25 & $\begin{array}{l}t_{(28)}=2.88, p<0.008 \\
\mathrm{p \eta}^{2}=0.27\end{array}$ \\
\hline $\begin{array}{l}\text { Peak knee abductor } \\
\text { moment }\left(\mathrm{N} \mathrm{m} \mathrm{kg}^{-1}\right)\end{array}$ & 0.54 & 0.19 & 0.82 & 0.20 & $\begin{array}{l}t_{(28)}=2.92, p<0.008 \\
\mathrm{p}^{2}=0.28\end{array}$ \\
\hline PTF (B.W.) & 3.25 & 0.46 & 3.84 & 0.45 & $\begin{array}{l}t_{(28)}=3.01, p<0.008 \\
\mathrm{p \eta}^{2}=0.29\end{array}$ \\
\hline PCP (MPa) & 7.96 & 1.30 & 9.27 & 1.36 & $\begin{array}{l}t_{(28)}=2.81, p<0.008 \\
\mathrm{p \eta}^{2}=0.26\end{array}$ \\
\hline Time to peak force (ms) & 0.07 & 0.01 & 0.07 & 0.02 & $\begin{array}{l}t_{(28)}=0.19, p>0.008 \\
\mathrm{p}^{2}=0.02\end{array}$ \\
\hline PTF load rate (B.W. $s^{-1}$ ) & 20.19 & 4.27 & 32.24 & 7.20 & $\begin{array}{l}t_{(28)}=2.74, p<0.008 \\
\mathrm{p \eta}^{2}=0.25\end{array}$ \\
\hline
\end{tabular}

A

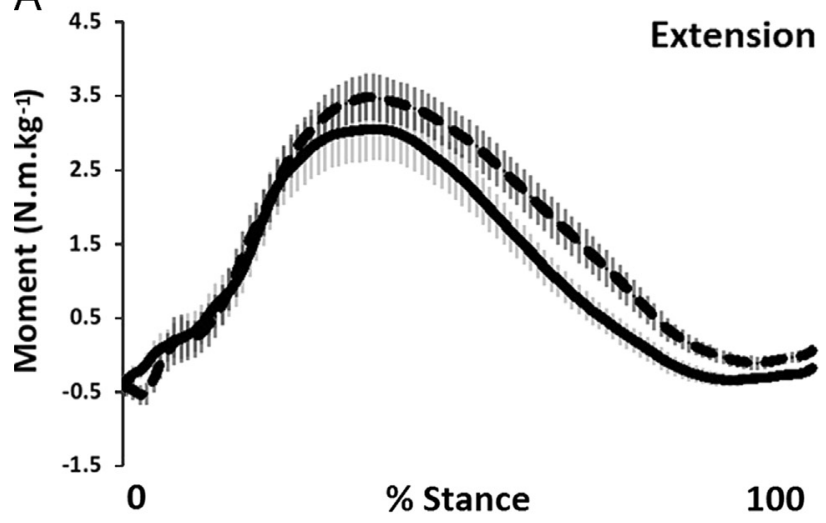

B

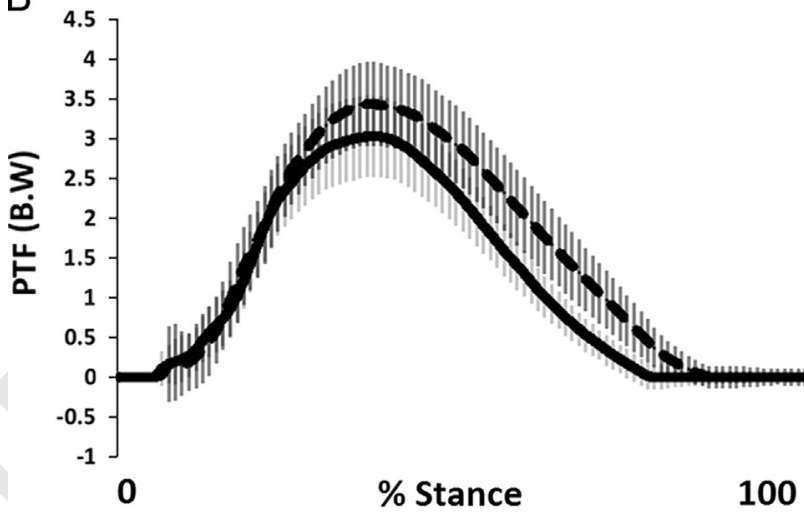

C exhibit reduced ankle plantarflexor moments and Achilles tendon Sinclair, 2014).
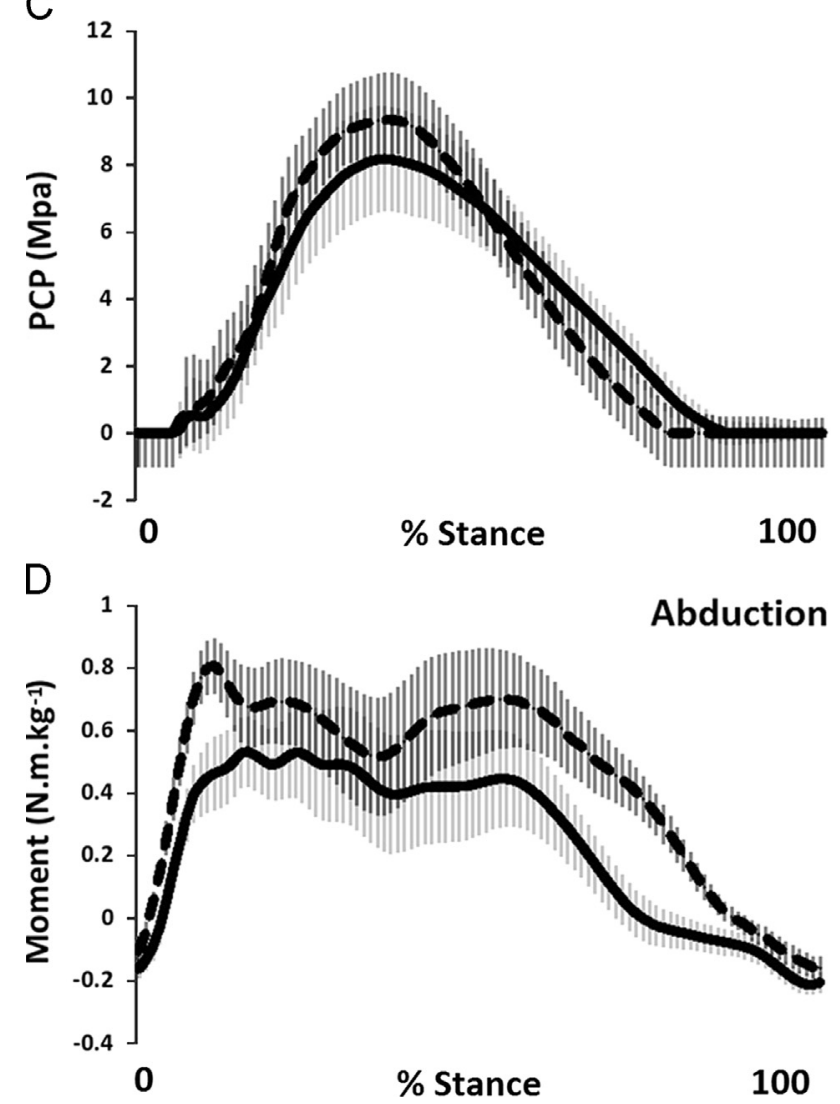

Fig. 1. Knee kinetics as a function of gender, black $=$ male and dash $=$ female ( $a=$ sagittal knee moment, $b=\mathrm{PTF}, c=\mathrm{PCP}$, and $d=$ coronal knee moment) (shaded area $=1 S D)$.

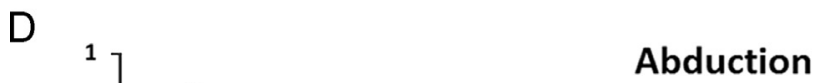


correspond with increased medial compartment loading (Zhao et al., 2007) and is commonly linked to the etiology and progression of degenerative knee syndromes such as medial tibiofemoral osteoarthritis (Miyazaki et al., 2002). Furthermore, it has also been postulated that increases in coronal plane moments during running serve to enhance loading of the lateral facet of the patellofemoral joint complex and thus may further contribute to the etiology of patellofemoral pain (Myer et al., 2015; Sigward et al., 2012).

A potential drawback of the current study is that patellofemoral forces were quantified using a mathematical model. This was necessary due to the invasive nature of obtaining direct measures of patellofemoral forces. The efficacy of this algorithm has yet to be resolved in the context of its effectiveness in quantifying sex differences in knee kinetics. This model has however been utilized previously on both male and female runners (Kulmala et al., 2013; Sinclair, 2014), also to successfully resolve differences in knee loads between sexes (Sinclair and Bottoms, 2015). However future work should nonetheless seek to develop a patellofemoral model which is specific to each sex. Muscle driven simulations of joint reaction forces using inverse kinematics have improved considerably in recent years and have thus been cited as a useful tool for clinical analysis (Delp et al., 2007). Musculoskeletal simulations however do require mechanical assumptions such as constrained rotational degrees of freedom at the joints which may lead to incorrectly predicted joint kinetics. Musculoskeletal simulation methods remain relatively new however and with further work to improve their accuracy further advancements in clinical biomechanics research may be possible.

In conclusion, the observations of the current investigation show that female recreational runner's exhibit significantly greater knee loading compared to males. Given the proposed relationship between knee joint loading and patellofemoral pathology, the current investigation does appear to provide some insight into the high incidence of patellofemoral pain in females. Future analyses may seek to implement strategies aimed at reducing knee loading in female runners. In addition it may be interesting to explore the loads relative to the preferred running speeds of the two sexes rather than running at a set speed for both.

\section{Conflict of interest statement}

No conflict of interest from any author.

\section{Acknowledgments}

Thanks to Glen Crook for his technical help and support throughout this work; and we wish him a very happy retirement.

\section{References}

Ahmed, A.M., Burke, D.L., Hyder, A., 1987. Force analysis of the patellar mechanism. J. Orthop. Res. 5, 69-85.

Bonacci, J., Vicenzino, B., Spratford, W., Collins, P., 2013. Take your shoes off to reduce patellofemoral joint stress during running. Br. J. Sport. Med. . http://dx. doi.org/10.1136/bjsports-2013-092160, Epub ahead of print

Besier, T.F., Gold, G.E., Beaupre, G.S., Delp, S.L., 2005. A modelling framework to estimate patellofemoral joint cartilage stress in vivo. Med. Sci. Sport. Exerc. 37, 1924-1931.

Boling, M., Padua, D., Marshall, S., Guskiewicz, K., Pyne, S., Beutler, A., 2010. Gender differences in the incidence and prevalence of patellofemoral pain syndrome. Scand. J. Med. Sci. Sport. 20, 725-730.

Cappozzo, A., Catani, F., Leardini, A., Benedeti, M.G., Della, C.U., 1995. Position and orientation in space of bones during movement: anatomical frame definition and determination. Clin. Biomech. 10, 171-178.
Cavanagh, P.R., Lafortune, M.A., 1980. Ground reaction forces in distance running. J. Biomech. 13, 397-406.

Crossley, K.M., 2014. Is patellofemoral osteoarthritis a common sequela of patellofemoral pain? Br. J. Sport. Med. 48, 409-410.

DeHaven, K.E., Lintner, D.M., 1986. Athletic injuries: comparison by age, sport, and gender. Am. J. Sport. Med. 14, 218-224.

Delp, S.L., Anderson, F.C., Arnold, A.S., Loan, P., Habib, A., John, C.T., Thelen, D.G., 2007. OpenSim: open-source software to create and analyze dynamic simulations of movement. IEEE Trans. Biomed. Eng. 54, 1940-1950.

Ferber, R., Davis, I.M., Williams, D.S., 2003. Gender differences in lower extremity mechanics during running. Clin. Biomech. 18, 350-357.

Greenhalgh, A., Sinclair, J., 2014. Comparison of Achilles tendon loading between male and female recreational runners. J. Hum. Kinet 44, 155-159.

Heino, B.J., Powers, C.M., 2002. Patellofemoral stress during walking in persons with and without patellofemoral pain. Med. Sci. Sport. Exerc. 34, 1582-1593.

Ho, K.Y., Blanchette, M.G., Powers, C.M., 2012. The influence of heel height on patellofemoral joint kinetics during walking. Gait Posture 36, 271-275.

Huberti, H.H., Hayes, W.C., 1984. Patellofemoral contact pressures. I. Bone Jt. Surg. 66, 715-724

Kannus, P., Aho, H., Jarvinen, M., Niittymaki, S., 1987. Computerized recording of visits to an outpatient sports clinic. Am. J. Sport. Med 15, 79-85.

Kulmala, J.P., Avela, J., Pasanen, K., Parkkari, J., 2013. Forefoot strikers exhibit lower running-induced knee loading than rearfoot strikers. Med. Sci. Sport. Exerc. 45, 2306-2313.

LaBella, C., 2004. Patellofemoral pain syndrome: evaluation and treatment. Prim. Care 31, 977-1003.

Mason, J.J., Leszko, F., Johnson, T., Komistek, R.D., 2008. Patellofemoral joint forces. J. Biomech. 41, 2337-2348.

McLean, S.G., Huang, X., Van Den Bogert, A.J., 2005. Association between lower extremity posture at contact and peak knee valgus moment during sidestepping: implications for ACL injury. Clin. Biomech. 20, 863-887.

Miyazaki, T., Wada, M., Kawahara, H., Sato, M., Baba, H., Shimada, S., 2002. Dynamic load at baseline can predict radiographic disease progression in medial compartment knee osteoarthritis. Ann. Rheum. Dis. 61, 617-622.

Mizuno, Y., Kumagai, M., Mattessich, S.M., Elias, J.J., Ramrattan, N., Cosgarea, A.J., Chao, E.Y., 2001. Q-angle influences tibiofemoral and patellofemoral kinematics. J. Orthop. Res. 19, 834-840.

Myer, D., Ford, K.R., Di, Stasi, S.L., Foss, K.D.B., Micheli, L.J., Hewett, T.E., 2015. High knee abduction moments are common risk factors for patellofemoral pain (PFP) and anterior cruciate ligament (ACL) injury in girls: is PFP itself a predictor for subsequent ACL injury? Br. J. Sport. Med. 49, 118-122.

Powers, C.M., Lilley, J.C., Lee, T.Q., 1998. The effects of axial and multiplane loading of the extensor mechanism on the patellofemoral joint. Clin. Biomech. 13, 616-624.

Powers, C.M., Chen, Y.J., Scher, I., Lee, T.Q., 2006. The influence of patellofemoral joint contact geometry on the modelling of three dimensional patellofemoral joint forces. J. Biomech. 39, 2783-2791.

Robinson, R.L., Nee, R.J., 2007. Analysis of hip strength in females seeking physical therapy treatment for unilateral patellofemoral pain syndrome. J. Orthop. Sport. Phys. Ther. 37, 232-238.

Selfe, J., Callaghan, M., Witvrouw, E., Richards, J., Dey, M.P., Sutton, C., Dixon, J., Martin, D., Stokes, M., Janssen, J., Ritchie, E., Turner, D., 2013. Targeted interventions for patellofemoral pain syndrome (TIPPS): classification of clinical subgroups. BMJ Open 3, e003795.

Sigward, S.M., Pollard, C.D., Powers, C.M., 2012. The influence of sex and maturation on landing biomechanics: implications for anterior cruciate ligament injury. Scand. J. Med. Sci. Sport. 22, 502-509.

Sinclair, J., Greenhalgh, A., Brooks, D., Edmundson, C.J., Hobbs, S.J., 2013. The influence of barefoot and barefoot-inspired footwear on the kinetics and kinematics of running in comparison to conventional running shoes. Footwear Sci. 5, 45-53.

Sinclair, J., 2014. Effects of barefoot and barefoot inspired footwear on knee and ankle loading during running. Clin. Biomech. 29, 395-399.

Sinclair, J., Bottoms, L., 2015. Gender differences in patellofemoral load during the epee fencing lunge. Res. Sport. Med. 23, 51-58.

Stearns, K.M., Keim, R.G., Powers, C.M., 2013. Influence of relative hip and knee extensor muscle strength on landing biomechanics. Med. Sci. Sport. Exerc. 45, 935-941.

Stefanik, J.J., Guermazi, A., Zhu, Y., Zumwalt, A.C., Gross, K.D., Clancy, M., Lynch, J.A., Segal, N.A., Lewis, C.E., Roemer, F.W., Powers, C.M., Felson, D.T., 2011. Quadriceps weakness, patella alta, and structural features of patellofemoral osteoarthritis. Arthritis Care Res. 63, 1391-1397.

Taunton, J.E., Ryan, M.B., Clement, D.B., McKenzie, D.C., Lloyd-Smith, D.R., Zumbo, B. D., 2003. A prospective study of running injuries: the Vancouver Sun Run "In Training" clinics. Br. J. Sport. Med. 37, 239-244.

Thomas, M.J., Wood, L., Selfe, J., Peat, G., 2010. Anterior knee pain in younger adults as a precursor to subsequent patellofemoral osteoarthritis: a systematic review. BMC Musculoskelet. Disord. 11, 201.

Tumia, N., Maffulli, N., 2002. Patellofemoral pain in female athletes. Sport. Med. Arthrosc. Rev. 10, 69-75.

van Eijden, T.M., Kouwenhoven, E., Verburg, J., Weijs, W.A., 1986. A mathematical model of the patellofemoral joint. J. Biomech. 19, 219-229.

van Gent, R.N., Siem, D., van Middelkoop, M., van Os, A.G., Bierma-Zeinstra, S.M.A., Koes, B.W., 2007. Incidence and determinants of lower extremity running injuries in long distance runners: a systematic review. Br. J. Sport. Med. 41, 469-480. 
Witvrouw, E., Callaghan, M.J., Stefanik, J.J., Noehren, B., Bazett-Jones, D.M., Willson, J.D., Earl-Boehm, J.E., Davis, I., Powers, C.M., McConnell, J., Crossley, K.M., 2014 Patellofemoral pain: consensus statement from the 3rd International Patellofemoral Pain Research Retreat held in Vancouver, September 2013. Br. J. Sport. Med. 48, 411-414.
Zhao, D., Banks, S.A., Mitchell, K.H., D’Lima, D.D., Colwell, C.W., Fregly, 2007. Correlation between the knee adduction torque and medial contact force for a variety of gait patterns. J. Orthop. Res. 25, 789-797.
Q467 